\title{
Territorios resilientes: mancomunales y concejos en el sur del Duero durante la Edad Media*
}

\section{Resilient territories: common areas and concejos in the southern Duero Valley during the Middle Ages}

Iñaki MARTín Viso

Universidad de Salamanca

viso@usal.es

Fecha de recepción: 08-04-2019

Fecha de aceptación: 10-07-2019

\section{RESUMEN}

Los estudios sobre el sur del Duero medieval han subrayado la importancia de los espacios comunales bajo control concejil. Se considera que su origen procede de la abundancia de baldíos en un territorio escasamente poblado y del interés ganadero de las elites de las villas. Sin embargo, la revisión de los datos existentes, tanto escritos como palinológicos, revela que se trataba de paisajes que ya estaban en uso antes del siglo XII, cuando se produjo la integración política en los reinos cristianos. La construcción del poder concejil se llevó a cabo mediante la afirmación de su función como garante de estas áreas. Se mantuvo así un modelo de usos que combinaba la propiedad concejil y el aprovechamiento por parte de los habitantes de las aldeas vecinas en el marco de unos territorios supralocales que mostraron una acusada resiliencia. Por tanto, la relevancia de los espacios comunales no provenía de una iniciativa sobre áreas baldías sino de la adecuación a una realidad preexistente, aunque a partir del siglo XII se produjeron cambios provocados por la redefinición y "politización" de tales áreas de uso mancomunal.

Palabras clave: Comunales, Concejos, Territorios, Ganadería, Aldeas

Topónimos: Sur de la Meseta del Duero

Período: Edad Media

ABSTRACT

Studies of the southern Duero Valley have highlighted the importance of the common spaces controlled by urban councils (concejos). According to those studies, their origin lay in the abundance of wastelands in a scarcely populated region and in the town elites' interest in livestock. However a review of written and palynological data reveals that these landscapes were in use before the 12th century, when the region was integrated into the Christian kingdoms. The shaping of council power

\footnotetext{
* Este trabajo forma parte del proyecto HAR2016-76094-C4-4-R financiado por el Ministerio de Ciencia, Innovación y Universidades.
} 
was achieved via affirmation of their function as guarantor of these areas. As a consequence, a pattern of uses was maintained that combined council ownership and the exploitation by the inhabitants of the neighbouring villages within the framework of particularly resilient supralocal territories. The relevance of the common spaces resulted not from the presence of wastelands, but from adaptation to a pre-existing reality, although from the 12th century onwards some changes occurred in relation to to the redefinition and "politicization" of these areas of common use.

Key words: Common rights, Urban systems, Territories, Livestock, Villages

Place names: Southern Duero plateau

Period: Middle Ages

\section{INTRODUCCIÓN: ESPACIOS COMUNALES Y CONCEJOS}

Tras la integración de la extensa región situada entre el río Duero y el Sistema Central en los reinos cristianos del norte, un proceso que se implementó entre finales del siglo XI y el último tercio del siglo XII, surgió una particular organización sociopolítica con grandes concejos que disfrutaban de una notable autonomía. El núcleo central, la villa, ejercía un dominio jurisdiccional sobre las aldeas que formaban la Tierra, aunque la definitiva cristalización de estas comunidades de villa y tierra no se produjo hasta la Baja Edad Media. Estos concejos eran sistemas políticos muy diferentes de los señoríos que se pueden observar en el norte del Duero, lo que provocó que fueran vistos como una suerte de áreas de libertad, una percepción que los trabajos efectuados en los años 80 del siglo pasado revelaron como incorrecta (Barrios García, 1983-84; Villar García 1986). En realidad, estaban controlados, aunque no monopolizados, por las elites de las villas, los caballeros villanos, así denominados por su identidad guerrera, aunque no eran propiamente una nobleza (Monsalvo Antón, 2003).

Un dato de enorme interés es la abundancia de espacios mancomunales concejiles, aquellos a los que tenían acceso los moradores de varias aldeas o comunidades, así como los propietarios de la villa concejil, y que se destinaban a pastos y a la recolección de leña, una situación que se documenta sobre todo a partir de la segunda mitad del siglo XIII. Estos mancomunales concejiles coexistían junto a los específicamente aldeanos, como ejidos y dehesas boyales, entre otros (Monsalvo Antón, 2002; Asenjo González, 1986: 179). En realidad, los mancomunales se diferenciaban de los comunales de aldea por la participación de varias comunidades (y no solo los moradores de una aldea) y por la intervención del concejo, por lo que formaban parte de la jurisdicción de la que disfrutaba la villa.

Se ha considerado que el origen de tales mancomunales estaría en la repoblación de estos territorios en el siglo XII, un proceso efectuado sobre un conjunto de territorios en el que predominaban las áreas baldías, pero también sería una consecuencia del importante papel de la ganadería en la construcción de los patrimonios de las elites concejiles (Asenjo González, 1999: 326; Barrios García, 1983-84; Martín Martín, 1990: 12-13; Monsalvo Antón, 2012-13). No sería una novedad; algunos testimonios evidencian un importante papel de la riqueza ganadera en época altomedieval, cuando estos espacios habrían estado organizados en comunidades de guerreros-pastores que emprendían ataques contra el área andalusí buscando hacerse con el ganado como botín (Villar García, 1986: 83). Por otra parte, esta actividad ganadera era central en la articulación de los patrimonios de la aristocracia duriense altomedieval (Mínguez Fernández, 1982: 353-354). En las serranías meridionales, la escasa población y las características geográficas (suelos muy ácidos y 
Figura 1. Localización de la zona de estudio y principales villas citadas en el texto

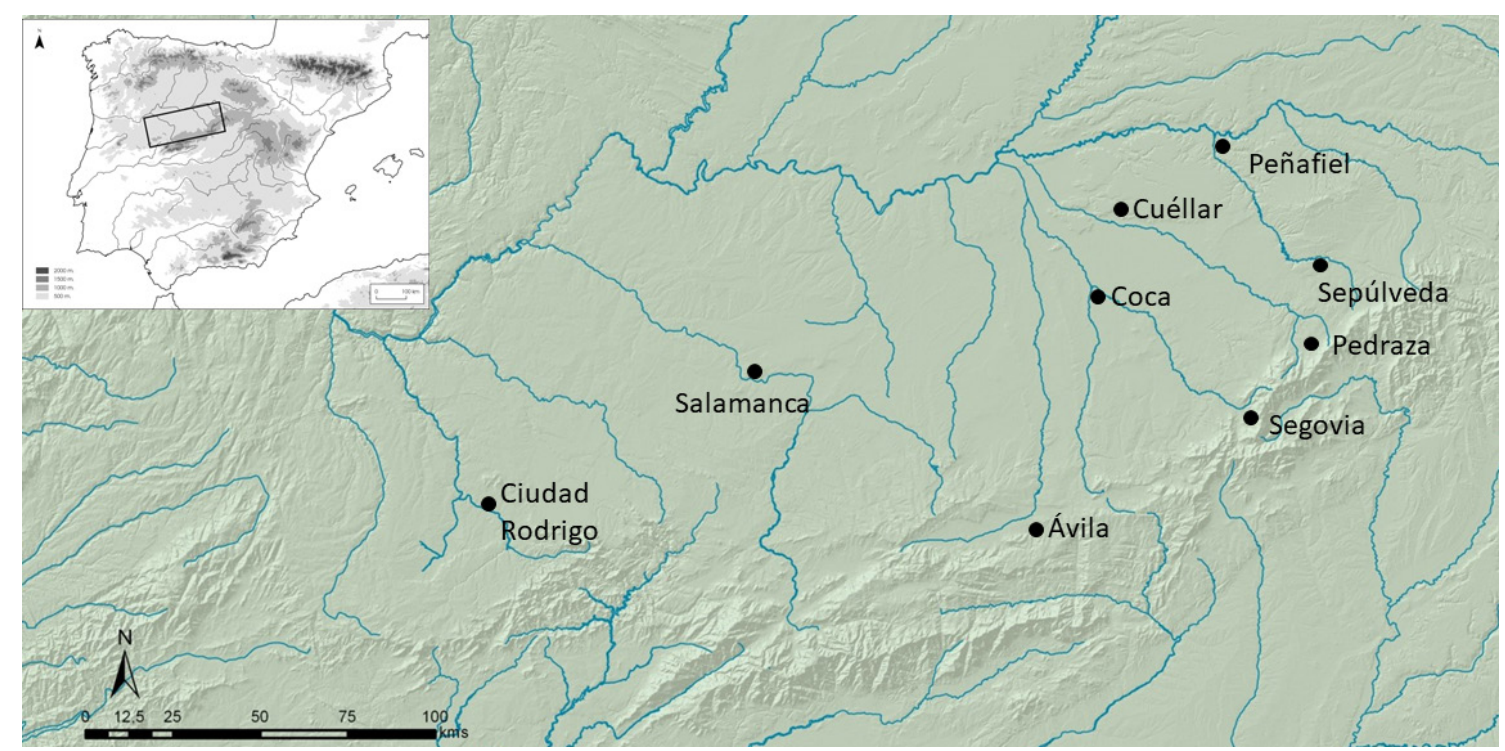

complementariedad de valles y montañas) habrían propiciado la presencia de áreas baldías y la especialización ganadera (Barrios García, 1983-84: II, 121-126). Sin embargo, los mancomunales concejiles se extendían más allá de los espacios de piedemonte y serranía, incluyendo áreas de llanura, como sucedía en los concejos de Cuéllar y Coca. También aquí los terrenos eran de escasa calidad, lo que posibilitó la expansión de usos madereros, con la expansión de los pinares en los siglos pleno y bajomedievales (Clement, 1993); pero parece que las condiciones geográficas no fueron el único factor. La dedicación a una u otra actividad y, sobre todo, la creación de modelos de gestión y de derechos de usufructo, son decisiones sociales. Sin duda las zonas serranas y de piedemonte tienen unas características muy específicas que dificultan la presencia de redes densas de asentamientos. Sin embargo, los espacios comunales medievales no surgieron solo en áreas de escasa densidad demográfica (Van Onacker, 2017). La pregunta que surge es si estas áreas estaban efectivamente abandonados o si, por el contrario, formaban parte de agrosistemas de larga tradición.

Los mancomunales concejiles comparecen en las fuentes escritas de manera muy tangencial. Únicamente en época bajomedieval podemos reconocer mejor su localización y gestión gracias a los pleitos entablados por los concejos a causa de las usurpaciones y abusos cometidos sobre ellos. Los análisis sobre esas usurpaciones dominan el panorama de la investigación y, gracias a ellos, se han podido abordar temas centrales sobre el papel de las elites urbanas y rurales (Asenjo González, 1999: 337-343; Monsalvo Antón, 2001 y 2007; Luchía, 2008), una situación que tiene claros paralelos en otras partes de la Península Ibérica (Cabrera Muñoz, 1978; Argente del Castillo, 1990: II, 572-605; Diago Hernando, 2009; García Oliva, 2017). Sin embargo, el énfasis en esta temática puede adentrarnos en una imagen cercana a la de la "tragedia de los comunales", es decir una crisis sistémica provocada por la ausencia de límites a los intereses individuales de los participantes en el recurso comunal (Hardin, 1968). Por el contrario, los comunales sobrevivieron y la información ofrece evidencias de una gestión destinada al control y la sostenibilidad de tales recursos (Ostrom, 1990). Por otra parte, los espacios comunales no se pueden definir exclusivamente a través de la propiedad jurídica; se trata de prácticas colectivas regidas por instituciones de escala local que regulaban derechos de aprovechamiento, donde la titularidad es menos importante que la aceptación de esas normas de uso (Asenjo 
González, 1986: 174; Luchía, 2005: 279). Podría admitirse que ambos aspectos, el relativo a la propiedad y el de las prácticas colectivas, se mueven en dos niveles diferentes que no se anulan entre sí: uno superior, relativo a la propiedad, y otro inferior, el de las prácticas colectivas que mantienen su autonomía con respecto a la propiedad.

El objetivo de este trabajo es analizar los procesos de formación y cambio de los espacios mancomunales en la zona del sur del Duero en una larga duración, para comprobar si efectivamente fueron el resultado de unas políticas concejiles específicas o, por el contrario, la adaptación de territorios y paisajes preexistentes. Para ello, se utilizarán los datos de los registros escrito y arqueológico, en especial la palinología, así como se partirá de la consideración de que estos recursos comunales no eran una reminiscencia arcaica sino fruto de una realidad socioeconómica compleja (De Moor, 2015).

\section{EL PAISAJE Y EL TERRITORIO ANTES DEL SIGLO XII}

Cuando se inició el proceso de integración política de los espacios al sur del Duero en los reinos cristianos ibéricos, estos territorios estaban ya poblados y existían agrosistemas complejos. A partir de las informaciones escritas, se ha establecido la imagen una región dominada por el bosque, con especial incidencia en los ámbitos serranos. No se trataría de una masa homogénea y densa, sino de un conjunto de manchas boscosas que progresivamente habrían ido desapareciendo como consecuencia de la roturación de tierras. En el caso de las tierras de montaña, habrían dado lugar a la creación de extensos pastizales de altura, como consecuencia del avance de la trashumancia (Barrios García, 1983-84: II, 83-93 y 121-126; Clément, 1994). Esta imagen debe contrastarse con los estudios palinológicos. Contamos con una visión de conjunto, que abarca a toda la zona serrana (Blanco González et al., 2015). Tras una fase de intensa deforestación e implantación de nuevos cultivos en el periodo posromano (400-700 A. D.), se produjo a partir del siglo VIII un retroceso de la presión antrópica. En el sector occidental, se mantuvieron las áreas de pasto y los cultivos de reducido tamaño en zonas de media altura así como en el llano, donde se detecta un descenso en la intensidad de la presión antrópica, aunque se mantuvo la actividad humana tanto ganadera como sobre todo cerealística, como sucede en el entorno de Salamanca (Ariño Gil, Riera i Mora y Rodríguez Hernández, 2002). Pero los registros polínicos de alta montaña muestran una fase de recuperación del bosque con el mantenimiento de usos ganaderos pero menos intensivos (López Sáez et al., 2009). En cambio, en la zona oriental, y especialmente en el área de Guadarrama, la actividad humana se intensificó. En algunas zonas, como la Sierra de Ojos Albos, la evidencia palinológica parece indicar la construcción de un paisaje ganadero de origen antrópico en el siglo VI que no se alteró sustancialmente hasta época contemporánea, por lo que hubo una cierta continuidad que abarcó todo el periodo altomedieval (Blanco González, López Sáez y López Merino, 2009: 291-292). La disminución de la presión antrópica se produjo exclusivamente en las zonas de alta montaña, que podían componer áreas de pasto relacionadas con usos trashumantes quizás más especializados, frente a lo que sucede en otras áreas, aquellas que no componían propiamente el estremo y donde posteriormente se observa una fuerte presencia de mancomunales. Puede desprenderse de estos datos un mantenimiento de los paisajes, con la excepción de aquellos que se corresponderían más tarde con la actividad ganadera, en un contexto de perduración de la producción campesina.

Hacia 950 A. D., el conjunto de informaciones existente permite observar un incremento de la deforestación en las áreas de alta montaña, como consecuencia de la explotación estacional de dichos espacios (Blanco González et al., 2015). En las zonas más bajas, el patrón es diferente, con una extensión del cultivo cerealístico, y unas actividades pastoriles que no conllevaban amplias roturaciones ni el uso extensivo del fuego, aunque 
en determinados lugares, como en La Meseguera, en la Peña de Francia, se detectan indicadores de pastos más visibles a través de la formación por fuego en torno al siglo XI. Un caso particular —en absoluto único — es Peña Negra, en la Sierra de Béjar, donde en torno al año mil se reconoce una intensa actividad ganadera, asociada a la irrigación y a la presencia de estructuras para el ganado (Abel Schaad y López Sáez, 2013). Puede identificarse una nueva fase en torno a 1120-1350, cuando el paisaje en los espacios montañosos vuelve a modificarse, con un decrecimiento del papel del cereal y un incremento de las actividades pastoriles gracias a la formación por fuego de pastizales, un momento claramente asociado a la eclosión de una trashumancia a gran escala, que rompe con las dinámicas previas. En áreas de llanura se ha comprobado la formación definitiva de los paisajes agrarios, con una fuerte deforestación, posiblemente a partir del año mil aproximadamente (Ariño Gil, Riera i Mora y Rodríguez Hernández, 2002). Los datos son fragmentarios, pero muy coherentes y muestran una secuencia de cambios, dentro de un paisaje articulado desde los siglos posromanos, a partir del siglo $\mathrm{X}$.

Los datos avalan que el agrosistema de los siglos XII y XIII sería el resultado de una serie de transformaciones pluriseculares y no una mera formación ex novo. De hecho, el punto de inflexión se produciría en torno al siglo $X$, aunque eso no significa que previamente el paisaje no estuviera antropizado. Se detecta la existencia efectiva de áreas de cultivo y de pastos antes de la "repoblación", mientras que la especialización ganadera de los espacios de alta montaña se produjo a partir del siglo XII.

La ausencia de datos sistemáticos es igualmente notoria en lo que se refiere a la presencia de asentamientos rurales. Para los siglos inmediatamente posteriores al final del imperio romano disponemos de datos sobre la presencia de algunos lugares habitados. Sin embargo, las evidencias disponibles hasta el momento no permiten afirmar su continuidad más allá del siglo VIII (Martín Viso et al., 2017; Tejerizo García, 2017: 221-228). Esta imagen no implica necesariamente una despoblación, ya que puede obedecer simplemente a las dinámicas propias del poblamiento rural, con procesos de creación y abandono de núcleos habitados de manera constante, o podría ser consecuencia de una distorsión provocada por el hecho de que muchos asentamientos rurales de época pleno y bajomedieval pudieron haber tenido un origen previo $\mathrm{y}$, al no formar despoblados, no han podido identificarse las fases altomedievales. La difícil calibración de las dataciones radiocarbónicas de este momento y el hecho de que la cultura material pudo no haber sufrido grandes modificaciones son otras razones que pueden estar ocultando la existencia de esos núcleos rurales. No obstante, se conocen algunos ejemplos de posibles asentamientos de larga duración. El más destacado es el yacimiento de Las Henrenes (Cillán, Ávila), del que se ha planteado una ocupación altomedieval que podría retrotraerse a siglos previos, ya que se han hallado algunas pizarras con signos numerales que se situarían en un horizonte posromano (Díaz de la Torre et al. 2009; Martín Viso 2015: 304). Este lugar puede identificarse con la población de San Cristóbal que figura en la documentación escrita del siglo XIV (Sobrino Chomón, 2009: docs. 31 y 77). Otro ejemplo, mucho más septentrional es el de La Huesa (Cañizal, Zamora), un lugar con una ocupación a partir del siglo VII, donde se han recuperado evidencias de una posible iglesia del siglo $X$ y que podría identificarse con el lugar de Villaralvo mencionado en 1116 (Presas Vías et al. 1994; Nuño González 1997-98; Ayala Martínez, 1995: doc. 6; Martín Viso, 2011: 129).

De nuevo, los datos existentes no son excesivamente numerosos y nos movemos más ante posibilidades que certezas. Pero este escenario parece ajustarse mejor a lo que nos informan otros indicadores como los análisis polínicos, con un paisaje antropizado, en el que pudieron existir abundantes espacios incultos. Sin embargo, esta afirmación no significa que tales áreas no tuvieran un valor en el agrosistema. 


\section{LATEMPRANAPRESENCIADE ESPACIOS DE USO COMUNAL Y MANCOMUNAL}

La documentación escrita revela la temprana presencia de comunales. Aunque el conjunto de textos conservados para finales del siglo XI y para el siglo XII no es muy cuantioso, pueden inferirse algunos datos relevantes. Uno de ellos es la presencia de sernas. Se trata de un término polisémico que en los siglos XII y XIII adquirió el significado de una prestación de trabajo (Alfonso, 1974; Botella Pombo, 1988: 60-62). Sin embargo, esa noción coexistió con otra anterior, de origen altomedieval, referida a un espacio de uso colectivo generalmente por parte de los habitantes de una aldea (Ortega Valcárcel, 1987; Botella Pombo, 1988: 24-48; Carvajal Castro, 2017: 162-170). En realidad, las menciones a sernas en la Meseta del Duero entre los siglos IX y XII son escuetas, si bien un análisis amplio ha permitido observar cómo funcionaban. Habría dos niveles de intervención: uno superior, asociado a reyes, aristócratas e instituciones religiosas, que aparecen con la "propiedad" de esas sernas, término que se relacionaba con su capacidad para salvaguardar los derechos de uso tradicionales; uno inferior, vinculado a campesinos que poseían parcelas o rationes dentro de las sernas, sobre las que tenían derechos de uso por pertenecer a colectivos que en algunas ocasiones son claramente comunidades rurales. La conexión entre ambos niveles se verificaba posiblemente a través del pago de algunas rentas. Era este sistema de usos colectivos y salvaguarda señorial lo que dotaba a la serna de contenido y no la producción, que podía ser muy diversa (Martín Viso, e.p.). Por otro lado, no hay una conexión directa entre las sernas como espacio y las sernas como prestación de trabajo, es decir que la obligación de la serna no se llevaba a cabo en una tierra denominada serna, por lo que debe pensarse en términos de desplazamiento del significado de una realidad a otra (García de Cortázar, 1980; Botella Pombo, 1988).

La presencia de estas sernas en el siglo XII no ha pasado desapercibida a los investigadores. Villar García (1986: 127-128) se hacía eco de su presencia y las entendía como espacios de uso colectivo, de origen autóctono, recientemente colonizados y, por tanto, excéntricos respecto al sistema de campos. Aunque el carácter marginal de las sernas haya sido matizado (Corbera Millán e Ingelmo Casado, 2011), la imagen de un espacio de uso colectivo puede sostenerse. Las referencias son muy parcas, pero algunos indicios parecen ir en esa dirección: en 1166, Alfonso VIII entregaba a Gutierre Miguel dos yugadas de año y vez en la serna de Espirdo, lo que podría fácilmente ilustrar la existencia de parcelas internas (Villar García, 1990: doc. 66). El hecho de que las sernas aparezcan en manos de señores e instituciones religiosas no debe entenderse como una muestra de que eran tierras sobre las que imponían prestaciones de trabajo, sino como la expresión de ese nivel superior de dominio que solo tenía sentido en un contexto de un espacio de uso colectivo.

Las sernas se mencionan de manera temprana en las fuentes escritas conservadas. Ya en 1086 se cita la serna que había recibido el monasterio de San Millán de la Cogolla en el valle de Balsamo, cerca de Navares, en el territorio de Sepúlveda tiempo atrás, posiblemente el pago de Vegas de San Millán, entre Navares y Urueñas (García Andreva, 2010: doc. CCXXX. g. 1). Durante los dos primeros tercios del siglo XII, se documentan algunas sernas más en distintos puntos del sur del Duero, un término relativamente frecuente, siempre dentro de las limitaciones que ofrece la escasa información preservada (Tabla 1). La mayoría de estas sernas se relacionan con aldeas, pero también se reconocen sernas asociadas a las villas concejiles, como es el caso de la de Espirdo —origen de la actual población homónima- que se encontraba en Segovia. En estos casos, quizás hubiera más de una serna, lo que explica que en Olmedo se mencione una serna menor en 1148 (Ayala Martínez, 1995: doc. 55; aparece por error del copista como serram minorem). Otro aspecto que cabe resaltar es el control regio sobre estas sernas durante este primer periodo. 
A partir de estos datos se puede formular la hipótesis de que hubiera un conjunto de bienes comunales en manos de las comunidades aldeanas y de las villas concejiles, y cuya existencia pudo haber sido anterior al proceso de integración política. Aunque los usos específicos sobre estas sernas no se explicitan, el interés de los reyes implicaría que eran algo más que zonas incultas. Por el contrario, formaban parte del abanico de recursos económicos de los que disponían las comunidades del sur del Duero. Pero también cabe pensar que eran uno de los cauces más importantes de la afirmación de identidades colectiva a escala local. Así se explicaría la presencia regia: los monarcas se hicieron, desde un tiempo muy temprano, con el control de estas sernas como un medio para afirmar su dominio local. La gestión cotidiana pudo mantenerse en manos de agentes locales o de la propia comunidad, pero los reyes asumieron la autoridad de salvaguarda como vía para legitimarse. Y lo hicieron en un momento en el que el poder concejil sobre el ámbito rural era todavía incipiente.

Tabla 1. Sernas documentadas en los primeros tiempos de la integración política del sur del Duero (1085-1175)

\begin{tabular}{|c|c|c|c|c|}
\hline Fecha & Localidad & Propietario & Receptor & Referencia \\
\hline 1085 & $\begin{array}{l}\text { Valle de } \\
\text { Balsamo } \\
\text { (cerca de } \\
\text { Navares) }\end{array}$ & Alfonso VI & $\begin{array}{l}\text { San Millán de } \\
\text { la Cogolla }\end{array}$ & $\begin{array}{c}\text { García } \\
\text { Andreva, } \\
\text { 2010: doc. } \\
\text { CCXXX.g.1 }\end{array}$ \\
\hline 1125 & $\begin{array}{l}\text { Brazuelas } \\
\text { (Alcazarén) }\end{array}$ & $\begin{array}{l}\text { Nuño } \\
\text { Serracín de } \\
\text { Portillo y su } \\
\text { mujer Eulalia }\end{array}$ & $\begin{array}{c}\text { Santo } \\
\text { Domingo de } \\
\text { Silos }\end{array}$ & $\begin{array}{l}\text { Vivancos } \\
\text { Gómez, } \\
\text { 1988: doc. } 40\end{array}$ \\
\hline 1135 & $\begin{array}{l}\text { San Pelayo } \\
\text { de Guareña }\end{array}$ & Alfonso VII & $\begin{array}{l}\text { Catedral de } \\
\text { Salamanca }\end{array}$ & $\begin{array}{l}\text { Guadalupe } \\
\text { Beraza et al., } \\
\text { 2010: doc. } 9\end{array}$ \\
\hline 1136 & $\begin{array}{l}\text { Yanguas de } \\
\text { Eresma }\end{array}$ & Alfonso VII & $\begin{array}{c}\text { Catedral de } \\
\text { Segovia }\end{array}$ & $\begin{array}{l}\text { Villar García, } \\
\text { 1990: doc. } 20\end{array}$ \\
\hline 1141 & Pedraza & Alfonso VII & $\begin{array}{l}\text { Domingo } \\
\text { Pérez de } \\
\text { Segovia }\end{array}$ & $\begin{array}{l}\text { Villar García, } \\
\text { 1990: doc. } 34\end{array}$ \\
\hline 1142 & Ávila & Alfonso VII & $\begin{array}{l}\text { Catedral de } \\
\text { Ávila }\end{array}$ & $\begin{array}{c}\text { Barrios } \\
\text { García, } 2004: \\
\text { doc. } 5\end{array}$ \\
\hline 1144 & Río Milanos & Alfonso VII & $\begin{array}{l}\text { Catedral de } \\
\text { Segovia }\end{array}$ & $\begin{array}{l}\text { Villar García, } \\
\text { 1990: doc. } 35\end{array}$ \\
\hline 1148 & Olmedo & $\begin{array}{l}\text { Infanta doña } \\
\text { Sancha, } \\
\text { hermana de } \\
\text { Alfonso VII }\end{array}$ & $\begin{array}{l}\text { Orden de } \\
\text { San Juan }\end{array}$ & $\begin{array}{c}\text { Ayala } \\
\text { Martínez, } \\
\text { 1995: doc. } 55\end{array}$ \\
\hline
\end{tabular}




\begin{tabular}{|c|c|c|c|c|}
\hline 1154 & Aguilafuente & Alfonso VII & $\begin{array}{c}\text { Catedral de } \\
\text { Segovia }\end{array}$ & $\begin{array}{c}\text { Villar García, } \\
\text { 1990: doc. 47 }\end{array}$ \\
\hline 1155 & $\begin{array}{c}\text { Fuentepelayo y } \\
\text { Navalmanzano }\end{array}$ & Alfonso VII & $\begin{array}{c}\text { Catedral de } \\
\text { Segovia }\end{array}$ & $\begin{array}{c}\text { Villar García, } \\
\text { 1990: doc. 48 }\end{array}$ \\
\hline 1164 & $\begin{array}{c}\text { Almenara, } \\
\text { Juzbado y } \\
\text { Baños de } \\
\text { Ledesma }\end{array}$ & Fernando II & $\begin{array}{c}\text { Catedral de } \\
\text { Salamanca }\end{array}$ & $\begin{array}{c}\text { Guadalupe } \\
\text { Beraza et al., } \\
\text { 2010: doc. 30 }\end{array}$ \\
\hline 1166 & Espirdo & Alfonso VIII & $\begin{array}{c}\text { Gutierre } \\
\text { Miguel }\end{array}$ & $\begin{array}{c}\text { Villar García, } \\
\text { 1990: doc. 66 }\end{array}$ \\
\hline 1171 & $\begin{array}{c}\text { Pedraza } \\
1174\end{array}$ & Alfonso VIII & $\begin{array}{c}\text { Catedral de } \\
\text { Segovia }\end{array}$ & $\begin{array}{c}\text { Villar García, } \\
\text { 1990: doc. 71 }\end{array}$ \\
\hline \multirow{2}{*}{1174} & $\begin{array}{c}\text { Espirdo } \\
\text { Carrascal del } \\
\text { de Almazán, } \\
\text { San Miguel } \\
\text { de Bernuy } \\
\text { y en el } \\
\text { término de } \\
\text { Fuentidueña }\end{array}$ & Alfonso VIII & $\begin{array}{c}\text { Gutierre } \\
\text { Miguel }\end{array}$ & $\begin{array}{c}\text { Villar García, } \\
\text { 1990: doc. 72 }\end{array}$ \\
\hline
\end{tabular}

Los concejos de las villas disponían también de derechos de tipo mancomunal sobre determinadas áreas desde tiempos tempranos. Cuando en 1076, Alfonso VI entregó el lugar de San Frutos del Duratón al monasterio de Santo Domingo de Silos y concedió al cenobio que disfrutase de pastos y de leña con los habitantes de Sepúlveda y de otras villas vecinas, exceptuando las dehesas en torno a San Frutos, que serán de uso exclusivo de los monjes (Vivancos Gómez, 1988: doc. 19). Este texto pone de relieve la presencia de usos mancomunales en el mismo año en que se reconocía el fuero a la comunidad de Sepúlveda por parte de Alfonso VI (Gambra, 1998: doc. 40; Monsalvo Antón, 2003: 61-66). El preámbulo de este documento subraya que es un ordenamiento que tuvo su origen en época de Fernán González, cuando se produjo la integración de Sepúlveda en el condado castellano, siendo posteriormente confirmado por los sucesivos condes. Sin embargo, es posible que este apartado, que parece haberse añadido con posterioridad, busque entroncar unas normas locales aplicadas por una comunidad política hasta entonces autónoma con un pasado condal, del que los reyes eran legítimos herederos, a fin de reforzar la profundidad histórica de la relación de Sepúlveda con el poder condal/regio. En cualquier caso, existen algunas evidencias de la presencia de una autoridad local, como reflejaría la existencia de un epígrafe que se ha datado en 1063 (Martín Aymerich, Tardío y Zamora, 1990: 126). Es muy probable que los usos mancomunados formasen parte del bagaje previo de la comunidad asentada en Sepúlveda, lo que explica su inmediata presencia en el justo momento en que se hace presente la intervención regia. El alcance geográfico de esta mancomunidad no debe exagerarse, ya que San Frutos se halla a unos 10 kms. en línea 
recta, por tanto un espacio cercano en torno a la villa de Sepúlveda. No es el único ejemplo. En 1103, los vecinos de Ávila donaron a San Millán de la Cogolla la iglesia de San Millán de Cierzo, incluyendo los derechos de pasto que tenían (García Andreva, 2010: doc. CCXXX, h. 1). No se sabe con certeza dónde se encontraba esa iglesia pero resulta evidente que existen desde el primer momento unos usos comunales ganaderos, si bien no está claro que fuesen de carácter mancomunal. La temprana presencia de estos espacios comunales reflejaría una ordenación territorial prexistente basada en la organización y gestión de áreas de uso comunal, que servían como áreas de obtención de recursos críticos (leña y pastos). Mostraba así la agencia política y social de las villas como comunidades políticas, que recibían un respaldo en la protección regia y su integración en el realengo.

Figura 2. Sepúlveda a finales del siglo XI

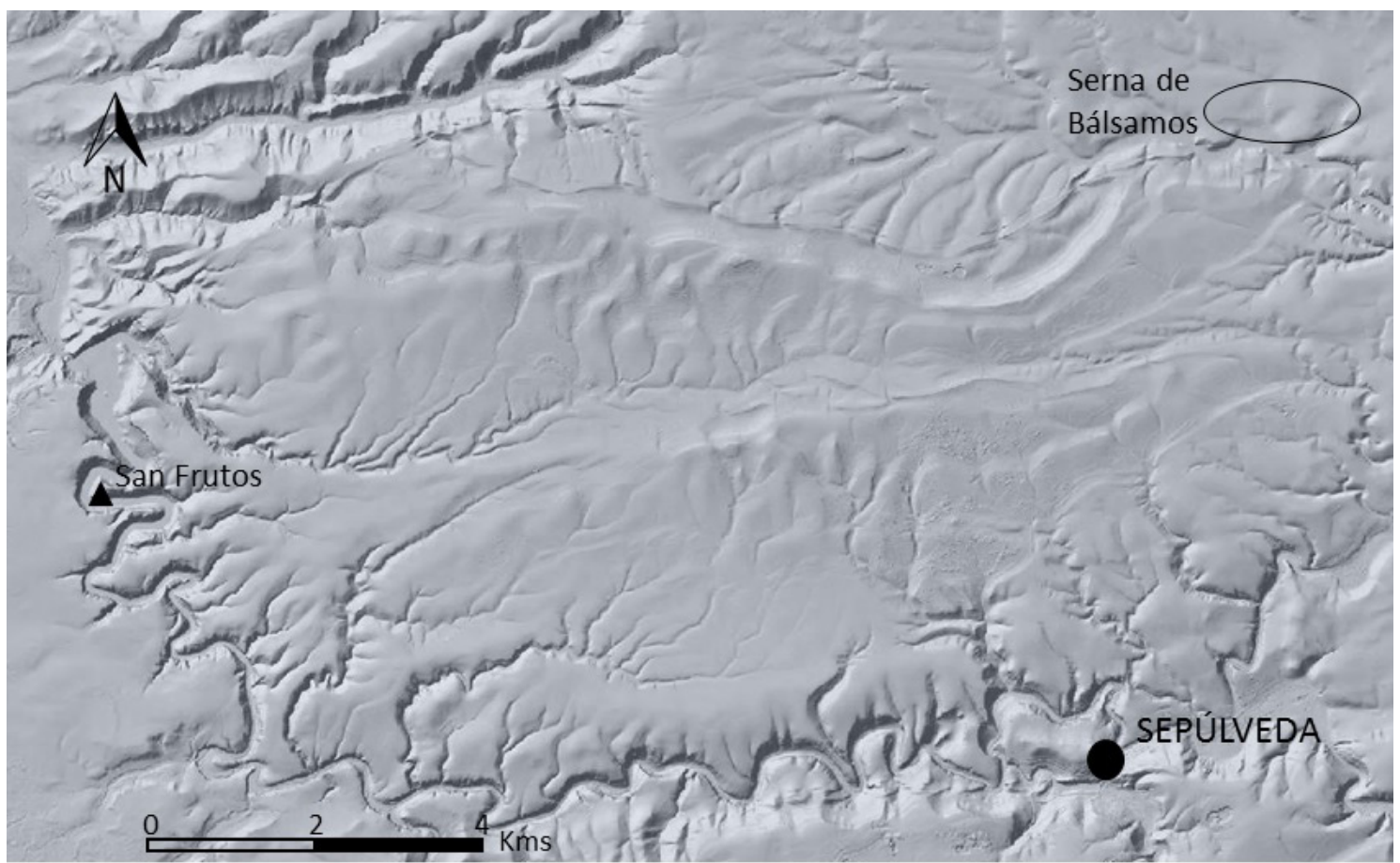

Al mismo tiempo coexistían espacios comunales de escala aldeana o comarcal, que no estaban directamente sujetos al control de los incipientes concejos. Las sernas muestran esa realidad en la que no hay evidencias de una intervención desde las villas, al menos en los tres primeros cuartos del siglo XII. Por el contrario, vemos al monarca redistribuyendo esos bienes, posiblemente como consecuencia de que disponía de ese control superior sobre esos espacios de uso colectivo. No queda claro, en cambio, que ese control estuviera necesariamente en manos de los concejos, al menos en el siglo XII. Las referencias a espacios de uso mancomunal asociados a las villas no comparecen en nuestras fuentes, si bien es cierto que la documentación concejil es prácticamente nula en este periodo. Pero ni siquiera las posibles referencias forales — por otro lado más tardías- se refieren a esos usos sino específicamente a las dehesas concejiles situadas en las inmediaciones de las cillas, como sucede con la dehesa del Zurguén en Salamanca, a pesar de que el territorio salmantino se extendía hasta zonas serranas (Martín y Coca, 1987: § 73-78). Es posible plantear, al menos como hipótesis, que la presencia de un control regio, sin que se explicite la participación del concejo, sería un indicio de la existencia de entramados sociopolíticos de pequeña escala, inferiores a las villas, pero que convivían con estas en un marco de fuerte fragmentación previa a la integración política de fines del XI. La configuración de 
un dominio concejil de los pastos mancomunales en la Tierra no fue un acto inmediato, sino que parece más plausible pensar en términos de un proceso de afirmación del poder jurisdiccional de las villas. En cambio, resulta difícil explicar cómo se pudo haber llevado a cabo de manera inmediata ese dominio, simplemente a través de un acto jurídico. Pensar en términos de progresivo control y de una previa articulación de los comunales concejiles en ámbitos geográficamente próximos (unos comunales propiamente de la villa) puede permitirnos comprender mejor la evolución.

\section{LA FORMACIÓN DE LOS TERRITORIOS CONCEJILES EN EL SIGLO XII}

Es interesante observar cómo algunos concejos, sobre todo los de menor tamaño, articulaban pequeños territorios definidos como espacios ganaderos de uso mancomunal, como Castelo Bom (Martín Viso, 2011: 126). Pero el proceso más frecuente fue la expansión del dominio concejil sobre áreas mancomunales hacia nuevas áreas. En el último cuarto del siglo XII, comienza a observarse cómo algunos de los concejos poseían intereses ganaderos que les llevaban a espacios relativamente alejados. Así ocurre con el concejo de Cuéllar que recibió del monasterio de Valbuena el acceso al río Duero a través de sendas cañadas que atravesaban Retuerta y Peñafiel, a cambio de que los hombres del monasterio pudieran cortar leña y que sus ganados pastaran en los bosques del concejo de Cuéllar, situados más al sur (González, 1960: doc. 616).

Algunos concejos tuvieron una amplia proyección territorial. En 1181, un documento de la cancillería de Alfonso VIII fijaba los límites del concejo abulense y, junto con la ya mencionada partición del Campo Azálvaro, se incluían espacios de sierra en el valle de los ríos Alberche y Perales, pero también zonas al sur de la Cordillera, como el valle del Tiétar (Luis López y Del Ser Quijano, 1990: doc. 1). Apenas doce años más tarde, el mismo monarca emitía un documento con una cuidadosa delimitación de los términos meridionales del concejo que abarcaba extensos territorios como el Campo Arañuelo y el valle del Jerte, así como el alto Tormes y zonas de la Sierra de Béjar (Luis López y Del Ser Quijano, 1990: doc. 3). Esta notable expansión se vio posteriormente limitada por las concesiones territoriales a las villas de Béjar y Plasencia, que absorbieron buena parte de estos términos (Luis López y Del Ser Quijano, 1990: docs. 5, 10, 11 y 12; González, 1960: doc. 520). Es muy probable que las concesiones del rey castellano obedeciesen a la necesidad de crear grandes marcos de encuadramiento, lo que explicaría que el dominio abulense fuese muy poco duradero. Pero algunas comarcas al sur del Sistema Central, como el Campo Arañuelo o el valle del Tiétar, quedaron bajo dominio del concejo de Ávila. E igualmente sucedió con los territorios del Alberche y del alto Tormes, en plenas serranías.

Segovia ofrece un panorama semejante, ya que su expansión se produjo sobre todo por el sur de la Sierra de Guadarrama. Dejando de lado su efímera presencia en el valle del Tajuña (González, 1960: doc. 547; García Luján, 1982: doc. 44), el concejo segoviano se hizo con el control de extensas tierras del norte y oeste de la actual provincia de Madrid, extendiéndose hasta Seseña. En ese lugar, se menciona la presencia de cañadas ya a mediados del siglo XII, una cita que ilustra el papel de los aprovechamientos ganaderos, aunque en este caso el control estaba en manos del obispo de Sigüenza (Minguella y Arnedo, 1910: doc. 30; González, 1960: doc. 385). Por otro lado, los segovianos se hicieron con el control del valle del Lozoya y del denominado Real del Manzanares, que fue objeto de una larga disputa con el concejo de Madrid. La concordia establecida por Fernando III en 1249 nos habla de la existencia de actividades ganaderas y de recolección de leña y el carácter de espacio comunal concejil de este sector, que se preservaba de otros posibles usos (González, 1980-86: doc. 784). 
Esta expansión hacia el sur posibilitó la ampliación de los territorios que se hallaban efectivamente $-\mathrm{y}$ no solo en un plano teórico- bajo control concejil. Como pone de manifiesto la mención a las cañadas en Seseña fue en esta zona donde se pudo crear un modelo de aprovechamiento basado en la trashumancia ganadera. Precisamente el control de los pastos debió ser una de las consecuencias más relevantes de toda la expansión. Estamos ante el territorio que constituye el estremo, es decir el límite de los concejos situado en las serranías del Sistema Central y en su vertiente meridional, donde la actividad ganadera era preponderante. En este contexto, pueden leerse los datos palinológicos que hablan de un considerable incremento de la deforestación en las áreas de montaña relacionada con el desarrollo de la actividad trashumante. Esta situación pudo haberse beneficiado de la ausencia de población en las áreas meridionales que habían estado en manos de los andalusíes. Pero no siempre fue así, ya que hay ejemplos de que algunas comunidades serranas poseían una estructura de bienes comunales organizada y sólida. En el valle de Valdeiglesias, los habitantes disponían de una serie de dehesas que preservaron de la actuación del monasterio de San Martín, tal y como se pone de manifiesto a comienzos del siglo XIII (González, 1960: doc. 772). Es significativa la mención a cuatro tumbas excavadas en la roca como uno de los límites de una de las dehesas, un eco de un modelo altomedieval que estaba en estos momentos diluyéndose.

Otros concejos, en cambio, no pudieron expandirse hacia el sur, por lo que fueron comunes los acuerdos entre ellos para compartir los usos de los espacios comunales limítrofes, como sucedió con los concejos de Fresno y Sepúlveda, así como con los de Cuéllar y Peñafiel, ambos en 1207 (González, 1960: docs. 809 y 817). En estos casos, la ausencia de una expansión territorial se suplió con el expediente de la formación de áreas mancomunales compartidas por varios concejos, un sistema que previamente ya había sido ensayado por los concejos de Ávila y Segovia en Campo Azálvaro.

Estos mancomunales son una realidad también al norte del Duero y posiblemente con un significado muy semejante al que aquí se plantea, es decir como parte de territorios de raíz local, como algunos alfoces. Pero la diferencia estriba tanto en la escala de esta realidad, que es mucho más abundante en el sur del Duero, como en el control desde las villas concejiles, algo que se percibe en menor medida al norte del Duero. Por tanto, la especificidad de los territorios meridionales del valle del Duero reside en la centralidad que tuvieron estos mancomunales en la construcción de los sistemas concejiles y su ubicua presencia.

\section{ESPACIOS MANCOMUNALES Y TERRITORIOS SUPRALOCALES}

La combinación de los datos anteriores pone de manifiesto que hubo probablemente espacios de uso comunal y mancomunal en el sur del valle del Duero desde antes de la integración en los reinos cristianos. La dinámica establecida por los concejos de las principales villas generó una tendencia a que el establecimiento del dominio concejil en espacios rurales se verificase a partir del control de esas áreas y su conversión en mancomunales concejiles. Esa situación se dejó sentir especialmente en las áreas del estremo, que se relacionaron rápidamente con las rutas de trashumancia, surgiendo un sistema económico de gran escala. En otras ocasiones, los concejos no tuvieron esa posibilidad, por lo que buscaron afianzar el control sobre los nuevos mancomunales concejiles, llegando en ocasiones a pactos sobre el aprovechamiento de áreas limítrofes.

Por otra parte, la configuración del paisaje relacionado con la trashumancia afectó sobre todo a las zonas de pasto de altura y a la formación de vías (cañadas). El problema era la alimentación del ganado en el tránsito hacia esas zonas de pasto, para lo que debieron habilitarse soluciones específicas. Pero no hay que considerar que las elites 
concejiles salieran necesariamente beneficiadas. En 1255, los procuradores del concejo de Ciudad Rodrigo se quejaban ante Alfonso $X$ porque vasallos de las órdenes militares y de otras villas que atravesaban el término concejil con sus ganados estaban destruyendo y quemando un pinar, un encinar y un robledal (Barrios García, Monsalvo Antón y Del Ser Quijano, 1988: doc. 2). Este documento revela las tensiones provocadas por el ganado trashumante; mientras el paisaje de los mancomunales concejiles estaba formado por una vegetación arbórea en forma posiblemente de un bosque no necesariamente tupido, los paisajes de la trashumancia buscaban la formación de pastizales extensos a través del uso del fuego. La respuesta concejil se inscribía no solo en la defensa de los derechos del concejo sino también en la necesidad de ofrecer amparo a los habitantes de las aldeas en el mantenimiento de los usos comunales, que habría sido un instrumento clave en la afirmación rural del dominio concejil. Esa salvaguarda, que correspondería a un segundo nivel dentro de la gestión de los comunales, referido a una propiedad superior, habría sido clave para permitir el acceso de los propietarios villanos a esas áreas de pasto.

Resulta conveniente centrarse en algunos casos específicos para comprobar cómo funcionaban en la práctica estas áreas de aprovechamiento mancomunal. La información es tardía, de los siglos XIV y XV, pero se reconocen elementos que podrían retrotraerse a tiempos previos. Un caso interesante es el que proporcionan los devasos, un conjunto de espacios mancomunales bajo control del concejo de Ciudad Rodrigo (Bernal Estévez, 1989: 117-126; Monsalvo Antón, 2007: 158-169). Un documento de 1376 recoge las declaraciones de los testigos convocados por el juez pesquisidor para que dieran noticia de las usurpaciones que se habían efectuado sobre los devasos de la Tierra de Ciudad Rodrigo (Barrios García, Monsalvo Antón y Del Ser Quijano, 1988: doc. 19). Este interesante documento ofrece una visión muy completa de la geografía de esos devasos, de sus usos y de los procesos de usurpación. Amplios espacios de la Tierra de Ciudad Rodrigo se organizaban bajo el régimen de devasos. Esto suponía la existencia de extensas áreas de uso mancomunal, que coexistían con dehesas para los bueyes y ejidos para los cerdos pertenecientes a las aldeas. Del testimonio de los testigos se infiere que los devasos eran utilizados por los propietarios de las aldeas vecinas, que llevaban sus ganados a pastar a estos lugares de manera conjunta. En el Campo de Argañán, los vecinos de Villar de Ciervo, Martillán, Villar de la Yegua y Mezquita "comen de buelta con sus ganados los términos de los dichos logares... los unos con los otros e los otros con los otros, guardando los panes e los prados de los bués". Es probable, por lo que se deduce de las ordenanzas de Ciudad Rodrigo de la primera mitad del siglo XV, que hubiese una norma que impidiese el majadeo nocturno y que limitase el número de cabezas de ganado (Barrios García, Monsalvo Antón y Del Ser Quijano, 1988: docs. 251 y 294), aunque en 1376 no se mencionan esos aspectos.

Un dato relevante es que no aparecen propietarios de la villa entre los beneficiarios; a pesar de que se citen los derechos de los vezinos de la Çibdat, casi todos los testigos son aldeanos de las proximidades. Martín Lorenzo Ardigo, de Perosín, afirmaba, en relación con la comarca y devaso de Robledo (actual El Rebollar) "que nunca sabe comer el dicho devaso a omes de fuera parte". El amplio conocimiento que tienen algunos propietarios de devasos emplazados lejos de sus aldeas podría estar indicando que los habían recorrido y utilizado. En el testimonio de Domingo Ramos, vecino de la Alberguería de Arriba, se ofrecen datos sobre Robledo, Valdeazaba y Campo de Argañán. Sin embargo, constituían una minoría y parece que en general los testigos solo estaban informados de los devasos relacionados con las aldeas que habitaban; por ejemplo, Domingo Pascual, vecino de Martillán, afirmó no saber nada sobre los devasos de Valdeazaba y de Robledo y da información de los lugares do dixo que comarcava, concretamente en el Campo de Argañán. En cambio, los dos únicos testigos de los que señala su condición de vecinos de Ciudad Rodrigo, Simón 
Alfonso y Alfonso Díaz, poseían una visión más global, ya que informaban de los devasos de Robledo, Valdeazaba, Campo de Argañán y Campo Carniceros, un indicio de que podían estar disfrutando de los usos en diversos lugares.

Figura 3. Localización de los devasos de Ciudad Rodrigo en 1376

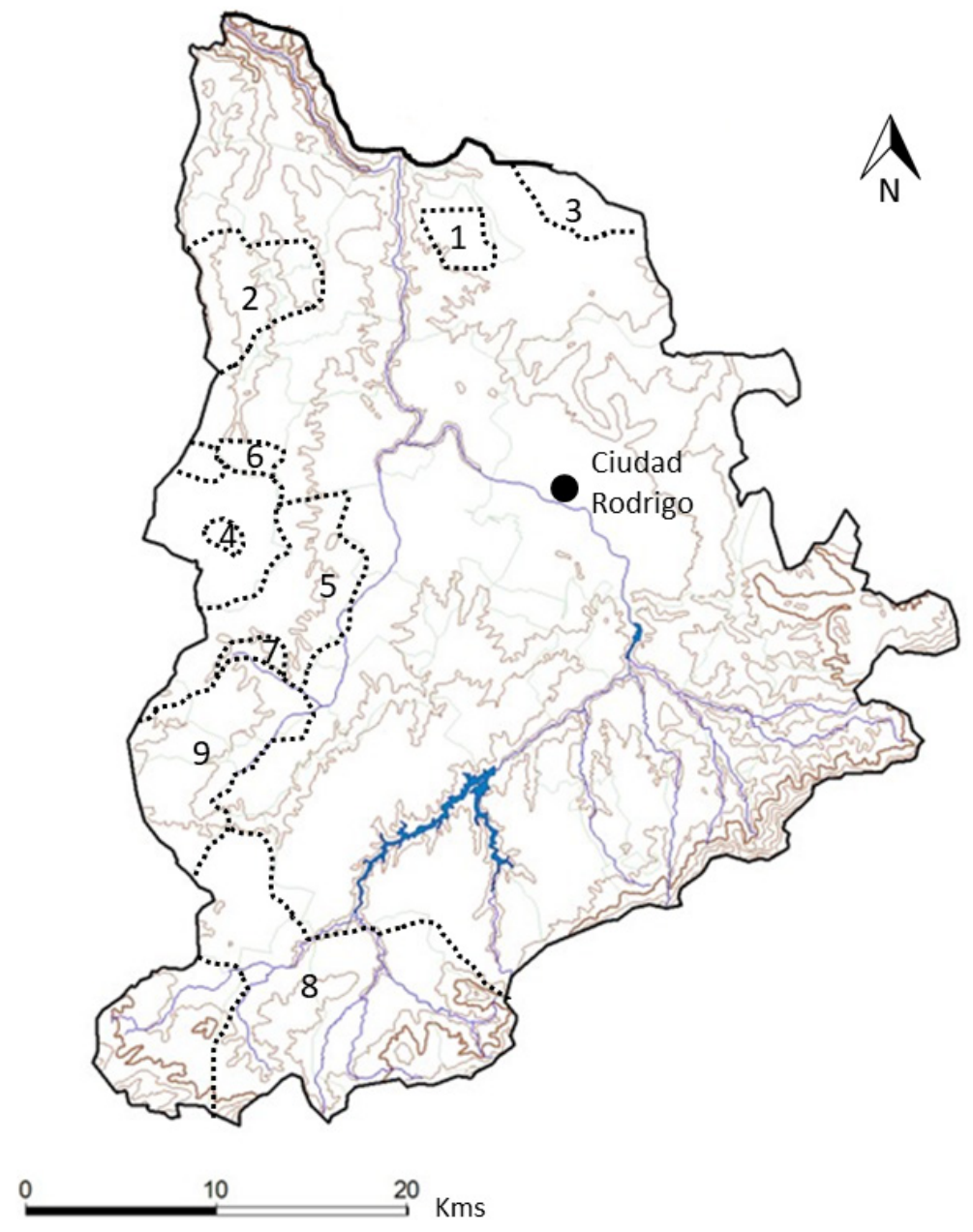

1) Balborraz; 2) Campo de Argañán (Villar de Ciervo-Aldea del Obispo-Villar de la Yegua-Mezquita); 3) Campo de Carniceros; 4) Dehesa del Águila; 5) Espeja-El Alcornocal; 6) La Mimbre; 7) Las Mohedas; 8) Robledo; 9) Valdeazaba (Ituero de Azaba-La Alamedilla-La Alberguería de Argañán). No localizados: Sotalvo y Valmanganiello-Valdemuelas.

Dentro de los espacios sometidos al régimen de devasos, se identificaban una serie de parajes específicos, conocidos por los vecinos que reconocían sus límites, aunque fueran difusos, como se desprende de la declaración de Domingo Ramos que habla de "un gran pedaço de tierra valdía, a do llaman la Binbre, que parte con la Alameda" (La Mimbre, paraje al sur de La Alameda de Gardón). En cuanto a las presiones a las que se veían sometidos, eran muy variadas: roturación de términos, apropiación y adehesamiento, así como imposición de cargas por el uso de los devasos son las más destacadas. El análisis de este tipo de abusos muestra cómo los habitantes de algunas aldeas se apropiaron de estos devasos, como los de Peñaparda y Fuentes de Oñoro; pero el grupo social más representado entre los "usurpadores" era el de la elite concejil (Monsalvo Antón, 2007: 167-168; Luchía, 2008). Este dato llama la atención frente a su ausencia entre el conjunto de usuarios que se beneficiaba del aprovechamiento de los devasos siguiendo las normas 
aceptadas. Esta situación parece indicar que, a pesar de la teórica posibilidad de que los propietarios de la villa pudieran usar los devasos, en la práctica esto era infrecuente. Las soluciones pasaban por hacerse vecino de una de las aldeas o por romper con el régimen existente y apropiarse de ese recurso. De todos modos, en la primera mitad del siglo XV, se documentan un conjunto de devasos en torno a la villa de Ciudad Rodrigo, que constituían el marco habitual de los usos comunales de los habitantes de las villas: Hamuxe, Cuesta del Obispo, Carazo, Capilla, Prado de San Martín, Serranos, Castellanos, y San Giraldo.

Resulta difícil comprender cómo era el paisaje físico. La única información palinológica procede de una turbera cercana al Paso de Santa Clara, en El Payo. Parece que en este punto existía una importante masa arbórea en época bajomedieval, aunque se detecta el uso del fuego para la creación de pastos, con un descenso de los alisos y un aumento de hongos coprófilos que denuncian la presencia de ganado. De todos modos, el impacto antrópico no es demasiado elevado hasta 1600, cuando se observa un descenso también del abedul frente al auge de las gramíneas y otras hierbas (Silva Sánchez et al., 2016). Por consiguiente, el impacto de la actividad ganadera en la Baja Edad Media fue real, aunque no demasiado intenso. Resulta complicado extrapolar este resultado al conjunto de la Tierra de Ciudad Rodrigo, ya que esta zona no aparece documentada en los siglos XIV y XV como un territorio de devasos. Ahora bien, si en estas zonas de posible uso trashumante el impacto no fue tan intenso, cabe imaginar que en aquellas áreas que preservaron unos usos extensivos debieron verse menos afectadas.

Los echos y alixares del concejo de Ávila presentan grandes similitudes, ya que eran los vecinos de las aldeas comarcanas y los propietarios del concejo los que podían disfrutar del uso de esos espacios mancomunados (Monsalvo Antón, 2002), pero, en la práctica, quienes más intensamente disfrutaban de ese aprovechamiento eran los propietarios de las aldeas vecinas. Esta situación permite plantearse la existencia de modelos de territorialidad de pequeña escala, sustentados en la identificación de los habitantes de unos pocos asentamientos con su condición de legítimos usuarios del bien mancomunado. Una realidad que coexistía con el reconocimiento de un control concejil superior que se movía en un nivel de salvaguarda de esos usos.

Esta territorialidad local muestra una considerable resiliencia y podría rastrearse su existencia en épocas tan tardías como el siglo XV. Al sur del Sistema Central, la villa de El Colmenar (actual Mombeltrán), que entró a formar parte del señorío primero de Álvaro de Luna y más tarde de Beltrán de la Cueva (Luis López, 2009: 158-213), conservó una serie de áreas de uso comunal (alixares) por el valle del Tiétar, que correspondían a la villa y a sus aldeas (Barrios García, Luis Corral y Riaño Pérez, 1996: docs. 40, 42, 43 y 44). Es posible interpretar este dato como la presencia previa de un pequeño territorio compartido por varios asentamientos - aunque uno pueda haber sido el principal- que disponían de unos lugares de uso comunal, cuyos límites y derechos de uso se precisaron debido a la segregación del concejo de Ávila de este lugar y de la vecina villa de Arenas de San Pedro. Quizás sucediera algo semejante en el caso de Navares de las Cuevas, Navares de Enmedio, Básamos, Urueñas y Castroserracín, pertenecientes al concejo de Sepúlveda enfrentadas a finales del siglo XV por la segregación de la primera de las aldeas al señorío del obispo de Burgos, lo que provocó tensiones por el uso de un monte en Navares de las Cuevas por parte de los habitantes del resto de los lugares (Sáez Sánchez, 1991: docs. $139,178,181$ y 195).

No obstante, esa territorialidad convivía en el siglo XIII con la concesión de términos propios a las aldeas por parte de los concejos dentro de un espacio difuso interaldeano, lo que reflejaría una identidad aldeana pujante (Luis López, 2006:191-196; Monsalvo, 2002). Las razones de este fenómeno son complejas y su análisis excede nuestros objetivos. En 
cualquier caso, iban más allá de la colmatación demográfica de unos espacios casi vacíos, ya que la ocupación de tales áreas tenía una larga historia (Blanco González y Martín Viso, 2016). Pero a ello se añade que en algunos casos podríamos encontrarnos ante la reorganización de esos territorios supralocales, que se redefinieron en términos aldeanos. Así ocurriría con Burgohondo, que en 1275 recibió del concejo de Ávila un heredamiento que incluía Navatalgordo, Navamuñoz, Navalosa, Navaluenga y otros lugares para que puedan tener donde labrar (Luis López y Ser Quijano, 1990: doc. 20).

\section{CONCLUSIONES: TERRITORIOS Y PAISAJES RESILIENTES}

La revisión de los datos que poseemos permite plantear una visión diferente con respecto al paradigma de una zona poco poblada, cuya organización mancomunal fue el producto de la necesidad de articular grandes espacios baldíos. En cambio, puede defenderse la idea de una región ocupada y organizada previamente, con espacios comunales y mancomunales tempranamente documentados. Estos parecen haber compuesto un recurso esencial de las poblaciones existentes en la zona antes de la "repoblación" y con la configuración de los grandes concejos de villa y tierra se produjo su integración en tales sistemas. Ese proceso pudo haberse implementado mediante la creación o apropiación por parte de los poderes concejiles de los derechos de salvaguarda sobre las áreas de uso comunal, que se convirtieron en mancomunales concejiles. Se trataba de un nivel superior de propiedad que coexistía con una propiedad mancomunal compartida por varias aldeas, cuya dimensión se centraba en la gestión cotidiana, de la que no parecen preocuparse tanto los concejos. Esta situación permite rastrear un tipo de territorialidad de escala supraldeana, pero inferior a la concejil, asociada a los derechos de uso mancomunal sobre determinados espacios. Esta territorialidad definía probablemente una identidad que agrupaba a los pobladores de unos pocos asentamientos. Una realidad de la que también bebían las villas cabeceras, que poseían a su alrededor una serie de bienes de uso comunal, aunque dispusieron de un radio de acción algo más extenso.

Es lícito pensar, aunque los datos no lo revelen, que en torno a estos territorios se crearon identidades locales basadas en el uso compartido de los comunales, que exigiría el desarrollo de unas normas básicas para su correcta gestión. Pero desde el siglo XIII fueron afirmándose nuevas identidades, amparadas en la implantación de la red parroquial (Blanco González y Martín Viso, 2016), que minaron las antiguas, aunque estas demostraron en algunos casos un alto grado de adaptación. De hecho, no debe interpretarse ambas identidades y territorialidades como excluyentes, sino que se solapaban. La temprana presencia de sernas en la documentación escrita sería un síntoma evidente de la existencia de lógicas comunales específicamente aldeanas. Esta situación puede definirse en términos de resiliencia, un concepto procedente de la ecología que se ha transmitido al estudio de las sociedades humanas, para definir su capacidad de transformación ante amenazas, desafíos o cambios externos (Keck y Sakdapulrak 2013). Un término que se ha aplicado a procesos sociales dinámicos de adaptación (Faulsteit 2016), pero que también puede aplicarse a los territorios en tanto construcciones sociales (Sack 1986). La centralidad aunque no exclusiva - de los espacios de uso comunal y sobre todo mancomunal habría sido una herencia del pasado altomedieval y no una aportación de las nuevas fuerzas sociales llegadas con la integración política, aunque no hubo una mera continuidad sino una reutilización de esos espacios y de los derechos creados en torno a ellos por parte de los nuevos actores. En ese sentido, podemos hablar de unos territorios resilientes.

Si esta interpretación es correcta, la percepción de una opción ganadera fruto de la confluencia entre una baja demografía y unos intereses ganaderos de las elites concejiles debe corregirse. Estos últimos no cabe descartarlos, pero no eran un rasgo diferenciador 
con respecto al conjunto de la población del sur del Duero. La diferencia estribaba en el hecho de que estos grupos asentados en las villas se convirtieron, gracias a los fueros, en una elite refrendada por el monarca y por un poder jurisdiccional que hasta entonces no poseían y que se fue lentamente construyendo. Una de las claves fue ejercer el control sobre los mancomunales, pero sin que ello supusiera un cambio sustancial en las economías locales. En tal caso, los concejos no habrían organizado un conjunto de espacios baldíos por sus intereses ganaderos, sino que habrían respetado los usos previos, sin que se produjera un deterioro profundo de los paisajes previos, salvo en zonas afectadas por la trashumancia. Las informaciones subrayan el papel de la ganadería, o en la zona de Tierra de Pinares la producción de carbón (García Fernández, 2004), pero se descuida un elemento que debió ser fundamental, como fue la recolección de leña, combustible básico y material de construcción, que debía ser fundamental para las comunidades locales medievales (Birrell, 1987).

Las razones de esta opción por los mancomunales no estribarían entonces en una suerte de arcaísmo social. En un medio natural con unas condiciones difíciles, los comunales y mancomunales representaban un recurso esencial para el mantenimiento de la cohesión de las comunidades. Complementaban los bienes obtenidos en parcelas agrarias de propiedad familiar, al proporcionar pastos para el ganado, leña y también recolección silvestre. El objetivo no era el mantenimiento de una igualdad social interna, como evitar el excesivo empobrecimiento y limitar la dependencia de las cosechas. La necesidad de gestionar estos recursos para su sostenimiento implicaba la creación de instituciones, de tipo informal, $y$, en definitiva, entraban a formar parte de una "economía moral" que sustentaba la idea de comunidad (Scott, 1979).

Desde esta perspectiva, la "repoblación" no aparece como el punto de partida de un paisaje social y físico, sino como una fase más dentro de una larga historia que hunde sus raíces en la Alta Edad Media. Pero esta afirmación no significa que hubiera simplemente continuidad. La integración política en los reinos cristianos representó un punto de inflexión que originó nuevas dinámicas. La inserción de los mancomunales en el paraguas concejil no fue un proceso inocuo. Por un lado, permitió a los propietarios de la villa la participación en tales áreas, modificando el equilibrio previo, si bien la efectiva presencia de estos propietarios no fue en absoluto masiva. Por otro lado, y quizás de manera más relevante, cambió la concepción de estos espacios. Hasta entonces habrían sido sobre todo derechos de uso, pero ahora se transformaron en propiedades concejiles, sin anular la existencia previa de esos derechos. Los pleitos del siglo XV sobre las usurpaciones vinculaban ya directamente el mantenimiento de los mancomunales concejiles con la idea de "bien común" y con nociones propias de un discurso político diferenciado del de los linajes concejiles (Monsalvo Antón, 2010), politizando su existencia (Mineo, 2014: 13-14). Un cambio fundamental: la "economía moral" se había desplazado hacia los concejos.

No fue la única alteración. Las dificultades a la hora de hacer efectivo el dominio sobre los espacios ganaderos pudo ser uno de los principales motores — no el único- para la expansión concejil sobre territorios al sur del Sistema Central, creando los estremos, en los que el papel de la trashumancia llegó a ser muy importante. En esas zonas el paisaje se modificó sustancialmente con la creación de pastizales. Pero también en las zonas más septentrionales los paisajes cambiaron. La dinámica económica facilitó que se incrementasen las áreas de cultivo e incluso pudo ser causante de la tendencia a que algunos baldíos se roturasen. Los espacios boscosos disminuyeron e incluso en ciertas áreas, con una dedicación a la producción del carbón, se produjeron cambios paisajísticos, con la presencia de nuevas especies, y avanzó la lógica territorial aldeano-parroquial. Sin embargo, todo ello coexistió con lógicas mancomunales que remitían a momentos anteriores, aunque se reconocen sobre todo por las modificaciones que sufrieron (por ejemplo, las segregaciones 
de aldeas a un señorío). En definitiva, fueron paisajes sociales con una evolución compleja, plasmado en territorios que podemos definir como resilientes, ya que eran el resultado de la adaptación por parte de las comunidades locales a las nuevas condiciones generadas tras la afirmación de los sistemas concejiles.

\section{BIBLIOGRAFÍA}

Abel Schaad, D. y López Sáez, J. A. (2013): "Vegetation change in relation to fire history and human activities at the Peña Negra mire (Béjar Range, Iberian Central Mountain System, Spain) during the past 4,000 years", Vegetation History and Archaeobotany, 22:3, pp. 199-214.

Alfonso, M. I. (1974): "Las sernas en León y Castilla. Contribución al estudio de las relaciones socioeconómicas en el marco del señorío medieval", Moneda y Crédito, 19, pp. 153210.

Ariño Gil, E., Riera i Mora, S. y Rodríguez Hernández, J. (2002): "De Roma al Medievo. Estructuras de hábitat y evolución del paisaje vegetal en el territorio de Salamanca", Zephyrus, 55, pp. 283-309.

Argente del Castillo, C. (1990): La ganadería medieval andaluza, siglos XIII-XVI (Reinos de Jaén y Córdoba), Jaén, Diputación Provincial de Jaén.

Asenjo González, M. (1986): Segovia. La ciudad y su tierra a fines del Medievo, Segovia, Diputación de Segovia.

- (1999): Espacio y sociedad en la Soria medieval (siglos XIII-XV), Soria, Diputación de Soria.

Ayala Martínez, C. de (1995): Libro de privilegios de la Orden de San Juan de Jerusalén en Castilla y León (siglos XII-XV), Madrid, Instituto Complutense de la Orden de Malta.

Barrios García, Á. (1983-84): Estructuras agrarias y de poder en Castilla. El ejemplo de Ávila (1085-1320), Salamanca, Universidad de Salamanca-Institución Gran Duque de Alba.

- (2004): Documentos de la catedral de Ávila (siglos XII-XIII), Ávila, Institución Gran Duque de Alba.

Barrios García, Á, Luis Corral, F. y Riaño Pérez, E. (1996): Documentación medieval del Archivo Municipal de Mombeltrán, Ávila, Institución Gran Duque de Alba.

Barrios García, Á., Monsalvo Antón, J. M. y Del Ser Quijano, G. (1988): Documentación medieval del archivo municipal de Ciudad Rodrigo, Salamanca, Diputación de Salamanca.

Bernal Estévez, Á. (1989): El concejo de Ciudad Rodrigo y su Tierra durante el siglo XV, Salamanca, Diputación de Salamanca.

Birrell, J. (1987): "Common rights in the medieval forest: disputes and conflicts in the thirteenth century", Past and Present, 117, pp. 22-49.

Blanco González, A., López Sáez, J. A. y López Merino, L. (2009): “Ocupación y uso del territorio en el sector centromeridional de la cuenca del Duero entre la Antigüedad y la Alta Edad Media (siglos I-XI d.C.)", Archivo Español de Arqueología, 82, pp. 275-300.

Blanco González, A. y Martín Viso, I. (2016): "Tumbas, parroquias y espacios ganaderos: configuración y evolución del paisaje medieval de la Sierra de Ávila", Historia Agraria, 69, pp. 11-41.

Blanco González, A. et alii (2015): "Medieval landscapes in the Spanish Central System (450-1350): a palaeoenvironmental and historical perspective", Journal of Medieval Iberian Studies, 7:1, pp. 1-17.

Botella Pombo, E. (1988): La serna: ocupación, organización y explotación del espacio en la Edad Media (800-1250), Santander, Tantín. 
Cabrera Muñoz, E. (1978), "Usurpación de tierras y abusos señoriales en la sierra cordobesa durante los siglos XIV y XV", en I Congreso de Historia de Andalucía, 2. Andalucía medieval, Córdoba, Caja de Ahorros de Córdoba, pp. 33-83.

Carvajal Castro, Á. (2017): "Prácticas colectivas y gestión de los espacios agrarios en la Alta Edad Media: una perspectiva comparada desde Irlanda y el noroeste de la Península Ibérica", Historia Agraria, 73, pp. 151-183.

Clément, V. (1993): "Frontière, reconquête et mutation des paysages végétaux entre Duero et Systéme Central du XI au milieu du XV siècle", Melanges de la Casa de Velázquez, 29:1, pp. 87-126.

- (1994): "La forêt et les hommes en Castille au XIII siècle: l'exemple du territoire de Sepúlveda", Mélanges de la Casa de Velázquez, 30:1, pp. 253-274.

Corbera Millán, M. e Ingelmo Casado, R. (2011): "Aportación a la historia de los terrazgos en la región cantábrica. Sernas en el valle del Saja y Liébana (Cantabria)", Historia Agraria, 55, pp. 13-45.

De Moor, T. (2015): The dilemma of the commoners. Understanding the use of commonpool resources in long-term perspective, Cambridge, Cambridge University Press.

Diado Hernando, M. (2009). "Las ocupaciones de términos en la Tierra de Cuenca a fines de la Edad Media: algunas peculiaridades locales de una práctica generalizada en la Corona de Castilla", en Val Valdivielso, M. I. y Martínez Sopena, P. (eds.), Castilla y el mundo feudal. Homenaje al profesor Julio Valdeón, Valladolid, Junta de Castilla y León, III, pp. 229-240.

- (2012): "Los aprovechamientos de las tierras de titularidad pública en las comunidades de Villa y Tierra de la Extremadura castellano-leonesa entre los siglos XIII y XVII", en Muñoz Gómez, V. (ed.), Las comunidades de villa y tierra. Dinámicas históricas y problemáticas actuales, Murcia, Universidad de Murcia, pp. 85-113.

Díaz de la Torre, J. et alii (2009): "El despoblado de San Cristóbal o Las Henrenes (Cillán, Ávila): una aproximación al paso de la Edad Antigua a la Edad Media en tierras abulenses", en Martín Viso, I. (ed.), ¿Tiempos oscuros? Territorio y sociedad en el centro de la Península Ibérica (siglos VII-X), Madrid, Sílex, pp. 159-180.

Faulsteit, R. K. (2016): "Collapse, resilience, and transformation in complex societies: modeling trends and understanding diversity", en Faulsteit, R. K. (ed.), Beyond collapse. Archaoelogical perspectives on resilience, revitalization, and transformation in complex societies, Carbondale, Southern Illinois University Press, pp. 3-26.

Gambra, A. (1998): Alfonso VI: cancillería, curia e imperio, León, Centro de Estudios San Isidoro.

García Andreva, F. (2010): El Becerro Galicano de San Millán de la Cogolla. Edición y estudio, Logroño, Fundación San Millán de la Cogolla.

García de Cortázar, J. Á. (1980): “La serna, una etapa del proceso de ocupación y explotación del espacio", En la España Medieval, 1, pp. 115-128.

García Fernández, J. (2004):" La explotación tradicional en la Tierra de Pinares segoviana", Investigaciones Geográficas, 35, pp. 5-23.

García Luján, J. A. (1982): Privilegios reales de la catedral de Toledo (1086-1462). Formación del patrimonio de la S.I.C.P. a través de las donaciones reales, Toledo, Caja de Ahorros Provincial.

García Oliva, M. D. (2017): "Usurpaciones de tierras comunales en el término de Plasencia a fines de la Edad Media", Studia Historica. Historia Medieval, 35:1, pp. 157-178.

González, J. (1960): El reino de Castilla en época de Alfonso VIII, Madrid, Escuela de Estudios Medievales.

- (1980-86): Reinado y diplomas de Fernando III, Córdoba, Caja de Ahorros. 
Guadalupe Beraza, M. L. et alii (2010): Colección documental del archivo de la catedral de Salamanca, I (1098-1300), León, Centro de Estudios San Isidoro.

Hardin, G. (1968): "The Tragedy of Commons", Science, 162, pp. 1243-1248.

Keck, M. y Sakdapulrak, P. (2013): "What is social resilience? Lessons learned and ways forward", Erdkunde, 67:1, pp. 5-19.

López Sáez, J. A. et alii (2009): "Contribución paleoambiental al estudio de la trashumancia en el sector abulense de la Sierra de Gredos", Hispania, 231, pp. 9-38.

Luchía, C. (2005): "Propiedad comunal y dedicaciones productivas en el área concejil castellana bajomedieval", Studia Historica. Historia Medieval, 23, pp. 275-295

- (2008): "Los pleitos por los términos comunales en el concejo de Ciudad Rodrigo en la Baja Edad Media", Historia, Instituciones, Documentos, 35, pp. 269-290.

Luis López, C. (2006): "Evolución del territorio y su proceso de señorialización”, en Del Ser Quijano, G. (coord.), Historia de Ávila, III. Edad Media (siglos XIV-XV), Ávila, Institución Gran Duque de Alba, pp. 177-211.

- (2009): "Villazgos señoriales en el sector meridional del alfoz a finales del siglo XIV", en Del ser Quijano, G. (coord.), Historia de Ávila. IV. Edad Media (siglos XIV-XV, $2^{a}$ parte), Ávila, Institución Gran Duque de Alba, pp. 113-260.

Luis López, C. y Del Ser Quijano, G. (1990): Documentación medieval del Asocio de la Extinguida Universidad y Tierra de Ávila, I, Ávila, Institución Gran Duque de Alba.

Martín, J. L. y Coca, J. (1987): Fuero de Salamanca, Salamanca, Diputación de Salamanca. Martín Aymerich, M. D., Tardío, T. y Zamora, A. (1990): Las murallas de Sepúlveda (Segovia). Un ensayo de aproximación con métodos arqueológicos a un ejemplo de pervivencia arquitectónica, Segovia, Diputación Provincial de Segovia.

Martín Martín, J. L. (1990): "Evolución de los bienes comunales en el siglo XV", Studia Historica. Historia Medieval, VIII, pp. 7-46.

Martín Viso, I. (2011): "Territorios supraldeanos y espacios de producción en el centro de la península ibérica (siglos X-XIII)", en Sabaté, F. y Brufal, J. (eds.), Els espais de secà. IV curs internacional d'Arqueologia Medieval, Lérida, Pagés Editors, pp. 117-143.

- (2015): "Huellas del poder: pizarras y poblados campesinos en el centro de la península ibérica (siglos V-VII)", Medievalismo, 25, pp. 285-314.

- (e.p.): "Commons and the construction of power in the early middle ages: tenth-century León and Castile", Journal of Medieval History.

Martín Viso, I. et alii (2017): "La formación de un nuevo paisaje en el centro de la península ibérica en el periodo posromano: el yacimiento de La Genestosa (Casillas de Flortes, Salamanca)", Archivo Español de Arqueología, 90, pp. 7-28.

Mineo, E. I. (2014): “Caritas e bene comune”, Storica, 59, pp. 7-56.

Minguella y Arnedo, T. (1910): Historia de la diócesis de Sigüenza y sus obispos, Madrid, Tipografía de la Revista de Archivos, Bibliotecas y Museos.

Mínguez y Fernández, J. M. (1982): "Ganadería, aristocracia y reconquista en la Edad Media castellana", Hispania, 151, pp. 341-354.

Monsalvo Antón, J. M. (2001): "Usurpaciones de comunales. Conflicto social y disputa legal en Ávila y su Tierra durante la Baja Edad Media", Historia Agraria, 24, pp. 89-122.

- (2002): "Espacios de pastoreo de la Tierra de Ávila. Algunas consideraciones sobre tipos y usos de los paisajes ganaderos bajomedievales", Cuadernos Abulenses, 31, pp. 139-196.

- (2003): "Frontera pionera, monarquía en expansión y formación de los concejos de Villa y Tierra. Relaciones de poder en el realengo concejil entre le Duero y la cuenca del Tajo (c.1072 -c.1222)", Arqueología y Territorio Medieval, 10:2, pp. 45-126.

- (2007): "Comunidades de aldea, comunales de ciudad-y-tierra. Algunos aspectos de 
los aprovechamientos comunitarios en los concejos medievales de Ciudad Rodrigo, Salamanca y Ávila", en Rodríguez, A. (ed.), El lugar del campesino. En torno a la obra de Reyna Pastor, Valencia, Publicaciones de la Universidad de Valencia, pp. 141-177.

- (2010): "Raíces sociales de los valores estamentales concejiles: la construcción de las mentalidades y culturas rurales de caballeros y pecheros (Ávila y su tierra, siglos XIIIXV)", en Monsalvo Antón, J. M., Comunalismo concejil abulense. Paisajes agrarios, conflicto y percepciones del espacio rural en la Tierra de Ávila y otros concejos medievales, Ávila, Institución Gran Duque de Alba, pp. 359-421.

- (2012-13): "Paisajes pastoriles y forestales en tierras salmantinas y abulenses. Aprovechamientos y cambios en los espacios rurales (ss. XII-XV)", Norba, 25-26, pp. 105-147.

Nuño González, J. (1997-98): “La Huesa, Cañizal (Zamora): ¿un asentamiento altomedieval en el "desierto" del Duero?", Numantia, 8, pp. 137-194.

Ortega Valcárcel, J. (1987): La Cantabria rural. Sobre "La Montaña", Santander, Universidad de Cantabria.

Ostrom, E. (1990): Governing the commons. The Evolution of the Institutions of Collective Action, Cambridge, Cambridge University Press.

Presas Vías, M. M. et alii (1994): "Excavaciones arqueológicas de urgencia en el Pago de la Huesa (Cañizal)", Anuario del Instituto de Estudios Zamoranos Florián de Ocampo, 11, pp. 43-57.

Sack, R. D. (1986): Human Territoriality. Its Theory and History, Cambridge, Cambridge University Press.

Sáez Sánchez, C. (1991): Colección diplomática de Sepúlveda, II, Segovia, Diputación de Segovia.

Scott, J. C. (1979): The Moral Economy of the Peasant: Rebellion and Subsistence in Southeast Asia, New Haven, Yale University Press.

Silva Sánchez, N. et alii (2016): "Influence of climate change and human activities on the organic and inorganic composition of peat during the 'Litte Ice Age' (El Payo mire, W. Spain)", The Holocene, 26:8, pp. 1290-1303.

Sobrino Chomón, T. (2009): Documentos de la Catedral de Ávila (1301-1355), Ávila, Institución Gran Duque de Alba.

Tejerizo García, C. (2017): Arqueología de las sociedades campesinas en la cuenca del Duero durante la Primera Edad Media, Bilbao, Universidad del País Vasco.

Van Onacker, E., (2017): Village elites and social structures in the late medieval Campine región, Turnhout, Brepols.

Villar García, L. M. (1986): La Extremadura castellano-leonesa. Guerreros, clérigos y campesinos (711-1252), Valladolid, Junta de Castilla y León.

- (1990): Documentación medieval de la catedral de Segovia (1115-1300), Salamanca, Universidad de Salamanca.

Vivancos Gómez, M. C. (1988): Documentación del monasterio de Santo Domingo de Silos (954-1254), Burgos, Garrido. 